\title{
Refugees' L2 learning: new perspectives on language motivation research
}

\author{
Monica Ortiz Cobo - Roman Kralik - Rosella Bianco
}

DOI: 10.18355/XL.2020.13.04.05

\begin{abstract}
This study analyses the factors that influence the second language learning motivation of refugees in Italy. To do so, we have conducted an ethnography by making interviews and questionnaires to adult refugee students of the Italian language. The analysis of the data highlights that the peculiar migration experience of this type of students results in specific language learning motivation factors. Starting by the existing paradigm, we discuss the refugee second language (L2) learning motivation as composed by the following dimensions: Ideal L2 Self, Ought-to L2 Self, Social Distance, Learning Experience, Self-confidence, and Anxiety and Multilingual Self.
\end{abstract}

Key words: motivation, language learning, L2MSS, refugees, second language

\section{Introduction}

The positive outcomes that a good motivation gives on learning are well known. However, literature has shown that not every motivation type gives the same learning result. In the field of language learning, Lambert demonstrated in 1969 that the level of linguistic competence depends on the type of motivation. In other words, depending on their motivation typology, students can achieve different levels of competence. On the other hand, it has also been shown that based on the type of motivation, the student will adapt his learning strategy, which in turn drives to a more or less good learning level (Oxford, Nyikos, 1989).

By putting its attention on the factors that influence the motivation of the students, the research in language learning motivation has been dedicated mainly to the English language learned as a foreign language (FL) in school contexts (Boo, Dornyei, Ryan, 2015). In contrast, much less attention has been given to the motivation to learn a language other than English (LOTE) and to a second language (L2), that is to say, a second language learned in the country where this language is spoken. Nevertheless, the global diffusion of migrations has incremented the learning of a second language, not as an educational goal, but as a means of integration in the country of migration. Consequently, second language learning motivation research has recently questioned the adaptability of the current paradigms (usually used for foreign language contexts) both to the contexts of second language learning and to the learning of a language different than the global English (Ushioda, Dornyei, 2017).

The work presented in this article aims at contributing to fill this gap of the research by analyzing the motivation of refugees and asylum seekers to learn the Italian language in Italy. As refugee migration experience and learning conditions are different than the ones of the rest of immigrants, we decided to circumscribe the study to this specific class of learners. The main objective of this research is to investigate the factors that influence the motivation of this type of students. By doing this, we study whether the learning of a second language in the peculiar condition of the forced migration is moved by specific motivations.

\section{The second language motivation research and the L2 Motivational Self System}

The first steps of language learning motivation research are taken by Gardner and Lambert, who recognized two types of motivation, the instrumental and the integrative (Gardner, 1985; Lambert, 1969; Gardner and Lambert, 1959). According to these authors, those who are moved by practical goals to learn a language (get a certificate, 
find a job, etc.) are influenced by an instrumental motivation. On the other hand, those who are interested in deepening their knowledge about the linguistic community and communicate with them are moved by an integrative motivation. Compared to instrumental motivation, integrative motivation is usually related to a higher level of linguistic competence. That is because this kind of motivation is usually stronger than the other one. In fact, integrative motivation is generally related to an affinity with the target language group. By living in the L2 country, the learner of this language is motivated by the need to integrate into the new country (Balboni, 2012).

The concept of integrative motivation is the foundational element of Gardner research, whose work, around sixty years ago, gave birth to the first stage of the second language motivation studies, defined as the social-psychological period (Dornyei and Ryan, 2005). Gardner and his colleagues worked on the L2 learning motivation, focusing on the affective factors related to language learning (Gardner, 2010). According to Gardner's theory, in order to learn an L2, the student needs to have an openness to the L2 community. Moreover, as stated by his theory, the L2 learning is greatly influenced by positive attitudes and motivation, while on the opposite, it is hindered by language anxiety. In order to test motivation, Gardner created the Attitude Motivation Test Battery (AMTB), a test battery that has been widely used and validated, due to Gardner's theory being the most diffused theory on this subject for many decades (Al Hoorie, 2017a).

Despite his great success, between the nineties and the first years of the third millennium, the L2 learning motivation theory witnessed a shift. The change relies on the passage from the social-psychological period to the cognitive one, which focuses its attention on the individual learner (Dornyei, Ryan, 2015). More in detail, the theoretical change consisted of the appearance of Dörnyei's theory in 2005. His theory is based on one hand on the idea of the possible selves proposed by Markus and Nurius (1986), which refers to the possible future representations of one's self. On the other hand, it originates from the self-discrepancy theory according to which there are two kinds of possible selves, the ideal self and the ought-to self, that in other words refer to what someone would like to be and what someone is ought to (Higgins, 1987). More specifically, Dörnyei expanded Gardner's theory and created the L2 Motivational Self System (L2MSS), which is the most used model at the moment (Boo, Dornyei, and Ryan, 2015). Three dimensions establish the L2MSS:

- the Ideal L2 Self that refers to the student identification with the community that speaks the L2. That is to say; it is the image of the ideal L2 speaker that the student aims to become in the future;

- the Ought-to L2 Self, which is related to the external expectations, namely the attributes that the student needs to have in order to fulfill the expectations of other people;

- the L2 Learning Experience that, as the name suggests, refers to the learning experience impact on student motivation; for example, the influence of the relation with the teacher, the classmates, or the school results (You, Dornyei, 2014).

In Dörnyei's theory, Gardner's concept of integrativeness was reinterpreted and substituted by the idea of the Ideal L2 Self (Dornyei, 2005). That is because, according to Dörnyei, integrativeness is only a facet of the L2 learner's Ideal Self. This change was thought to suit the learners of a foreign language, as "in the absence of a salient L2 group in the learners' environment (as is often the case in foreign language learning contexts in which the L2 is primarily learned as a school subject) the identification can be generalized to the cultural and intellectual values associated with the language, as well as to the actual L2 itself" (Dornyei, Csizer, 2002:453). Nevertheless, the shift towards including integrativeness into the Ideal L2 Self was not meant to make the L2MSS suitable for foreign language learners only, but to include both cases, L2 learners and FL learners, into the same motivation system. This is made clear by

XLinguae, Volume 13 Issue 4, October 2020, ISSN 1337-8384, ISSN 2453-711X 
Dörnyei and Csizér when they say: "We suspect that the motivation dimension captured by the term is not so much related to any actual or metaphorical, integration into an L2 community as to some more basic identification process within the individual's self-concept. As described above, such a conception would not conflict with the original Gardnerian notion and would at the same time provide a broader frame of reference: it could explain the motivational setup within diverse learning contexts even if they offer little or no contact with the L2 speakers (...)" (Dornyei, Csizer, 2002:453). On the other hand, the concept of the instrumentality of the learning is associated with both Ideal L2 Self and Ought-to L2 Self. That because, according to the new theory, instrumentality can have a promotion focus, hence being a facet of the Ideal L2 Self, or a prevention focus, in which case is a part of the Ought-to L2 Self (Dornyei, 2010a).

In order to have a closer look at the L2MSS, it is necessary to observe the main research instrument used in the literature, the questionnaire. A good example of a questionnaire is the one used in the work of Taguchi, Magid, and Papi (2009). They carried out a survey in Japan, Iran, and China. The results of their work validated the L2MSS in these countries and the dimension of integrativeness as a part of the Ideal L2 Self. In order to formulate the questionnaires, the authors took into consideration the leading work of Dörnyei, Csizér, and Németh (2006), but also those of Ryan (2009), Yashima et al. (2004), Dörnyei (2001), Noels et al. (2000), Clément and Baker (2001), Neuliep and McCroskey (1997) and Gardner (1985). From the combined list of the items included in the questionnaire, it is possible to better observe the L2MSS and have a look at the factors affecting the motivation that has been considered in the literature. Ten factors were taken into consideration by the work of Taguchi, Magid, and Papi (2009):

- Criterion measures evaluate the intended effort of the student;

- Ideal L2 Self assesses the identification of the student with his future image of an L2 speaker;

- Ought-to L2 Self values the characteristics that the student believes he ought to possess to please the other people expectations;

- Family influence measures the role of the family in the student motivation;

- Instrumentality-promotion evaluates the relation of the student L2 learning motivation with his personal life goals;

- Instrumentality-prevention measures the relation of the duty to study the language in order to satisfy an obligation;

- Attitudes to learning English calculates the learning reasons related to the immediate experience;

- Attitudes to L2 community evaluates the student's attitudes towards the L2 community;

- Cultural interest estimates the interest of the student in the cultural products of the L2 society;

- Integrativeness assesses the positive attitudes of the learner toward the L2 community, language, and culture.

As anticipated earlier, integrativeness has been included in the L2MSS as a facet of the L2 Ideal Self. Between the other factors, it is interesting to note that, although the Ought-to L2 Self includes general questions about external pressure on studying the L2 (e.g. "Learning English is necessary because people surrounding me expect me to do so"), a big importance is given to the influence of the family members, due to the fact that this system is usually used to test learners at school age (Dornyei, 2010b). This is an important point for our research when coming to the analysis of the factors used by the literature that can be adaptable to our specific learners' group of the refugees. That is because our goal is to understand the factors that can be related to the motivation of refugee students, that is, to say, adult learners of an L2 with very specific living conditions. Another point that looks relevant for this purpose is the factor of 
the cultural interest, which seems to be prior to a foreign language student that studies for his education rather than to an L2 adult learner who studies a language in order to live in its country.

Besides the main theoretical thread on second language motivation, we urge to mention other secondary aspects that need to be taken into consideration when discussing the motivation of an L2 learner. First of all, it is essential to remember the hypothesis of the affective filter proposed by Krashen (1982), which considers the existence of three variables that can hinder the acquisition process: motivation, anxiety, and selfconfidence. Surely, we consider that for the special situation of the refugees living conditions, these factors can be relevant to their learning process. Moreover, both anxiety and self-confidence can have an impact on their learning motivation. Another factor that is important for this research is the relation of the social distance with second language learning. As Schumann says, "It is argued that social distance and hence a bad language learning situation will exist where the 2LL group is either dominant or subordinate, where both groups desire preservation and high enclosure for the 2LL group, where the 2LL group is both cohesive and large, where the two cultures are not congruent, where the two groups hold negative attitudes toward each other and where the 2LL group intends to remain in the target language area only for a short time" (Schumann, 1976:135). The factors that, according to Schumann can trigger social distance - and for instance, can hinder second language learning - seems to be relevant for our context, as for being forced migrants, refugees could particularly suffer from situations that trigger social distance with the target language community. Finally, as a conclusion of this section, we find it meaningful to mention the motivational model of Balboni (2012), according to whom we have three main sources of motivation: il dovere (the duty), il bisogno (the need) and il piacere (the pleasure). If we consider the need for integrating into the L2 community, we find that an immigrant could be moved to learn the second language mainly due to duty and need. Pleasure, on the other hand, could appear in case the migrant is also moved by an affective factor and shows positive attitudes and closeness towards the L2 society.

\section{New paths for the second language motivation research}

The present of the second language motivation research is being characterized by new changes and emerging interests. Dörnyei and Ryan define the current period as the socio-dynamic one (Dornyei, Ryan, 2015), due to the assumption that the motivation of a learner is not stable but can change over time and depending on the context. Moreover, several are open theoretical issues that characterize the current period. Nevertheless, in this context, we find it convenient to define expressly those that are more relevant to the contextualization of our study.

First of all, it must be highlighted that language learning motivation research has focused till now for more than $70 \%$ on English language learning. This is basically due to the status and the particular roles that the English language covers in the global context (Boo, Dornyei, Ryan, 2015). On the one hand, this shows that there is an evident lack of research on language motivation that refers to languages other than English; on the other hand, it raises the question of whether the theoretical paradigms used over the last decades can be applicable to the study of the motivation of other languages. It has to be noted that, due to its status, English learning motivation could be different than the motivation to learn a LOTE. Likewise, English global status could cause the learning of English to have an influence on the motivation of learning a LOTE. In addition, it is assumed that in the contemporary learning of English and a LOTE there could be motivational interferences between the two languages (Ushioda , Dornyei, 2017).

At the same time, the disproportionate number of research between English and the other languages warns on the neglecting of the important human mobility phenomena

XLinguae, Volume 13 Issue 4, October 2020, ISSN 1337-8384, ISSN 2453-711X 
witnessed worldwide. That is relevant because human mobility involves significant numbers of immigrants learning an L2. In other words, the literature has focused mainly on the learning of English as a global-foreign language, neglecting the world of the L2. As state of the art suggests, there is a need for validating the L2MSS as a model in second language contexts (Dornyei, Al Hoorie, 2017). For this reason, the motivation to learn a LOTE as an L2 is an emerging research topic that must take into account questioning the traditional research models that are used for the study of global English.

One important aspect is the revaluation of the integrative factor in the case of LOTE. As Hoorie says, "One interesting outcome of researching LOTEs is that the role in integrative motivation seems to resurface. Integrative motivation might be a relevant concept in the context of LOTEs as there is usually a specific community out there that speaks the language, and that is considered the "owner" of that language. In addition, many individuals who decide to take up learning a certain LOTE do so because they are already in the geographical area where the language is spoken or because they plan to move there" (Al Hoorie, 2017b:7). Indeed, integrative motivation seems to be a more important factor for L2 learners rather than foreign language learners (Oxford, 1996).

Another aspect that needs to be taken into account is the Ought-to L2 Self dimension. It has been hypothesized that different from the global English that has a homogenous Ought-to L2 Self, the Ought-to L2 Self of a LOTE's learner could be more fragmented, at the point that it could consist of multiple dimensions (Dornyei, Al Hoorie, 2017). Besides this, we consider that it is essential to highlight some other particularities of the Ought-to L2 Self that could be relevant for studying motivation in L2 contexts concerning immigrant learners. First of all, we need to take into account that the Ought-to L2 Self dimension has been found to be correlated with anxiety (Papi, 2010). Likewise, it has been argued that the Ideal L2 Self is incompatible with a contrasting Ought-to L2 Self, as this could be counterproductive in language learning (Dornyei, Ushioda, 2011; Dornyei, 2009). About this, Dörnyei and Al-Hoorie (2017) remind us of various studies that discuss the reactance to external expectations. In order to preserve their freedom, some people react to an external expectation by behaving in the opposite way (Chartrand, Dalton and Fitzsimons, 2007). That means that when the learning of a language is imposed by external expectations, the learner could react by desiring to learn another language or by refusing to learn the prescribed one. Surely, such imposition could have originated from family but also from society, the latter being the case addressed by Sugiharto (2015) work, which describes how in a nationalist country that pushes on the preservation of the local languages, people react by keeping talking English. This aspect of motivational research is of particular interest because, as Lanvers (2017) shows, there is a lack of works that relate social factors or xenophobia to language learning motivation.

In this regard, it must be highlighted that immigration and language learning are strictly correlated and undergo prescriptions and rules from society and governments (Pulinx, Van Avermaet, Extramiana, 2014). That because, due to the global diffusion of migrations, language learning is not limited anymore just to the cultural education of a student, but it has acquired importance for the migrants' integration in the new socio-cultural context (De Mauro, Vedovelli, Barni, Miraglia, 2003). This is due to the need to be able to communicate their own thoughts in order to participate in civic life (Zalec, Pavlikova, 2019). Despite this, only a few studies investigated the language learning motivation in these contexts. Between the existing researches, the work of Li Qi (2014) validated the L2MSS in the L2 context by making a comparison of its use in both second and foreign language contexts. The results of his work show relevant differences between the motivations of L2 and FL learners, with L2 learners being more motivated than the others. Besides this study, one of Stracke, Jones and Bramley (2014) also tested the L2MSS between L2 immigrant learners. In their work, 
attitudes towards L1 and L2 are investigated, and the results show the development of a bicultural identity. Nevertheless, as in most of cases of foreign language learning motivation, these two studies regarded the learning of English language. After all, we can confirm that LOTE motivation research is very scarce and needs further investigations. Moreover, the research needs to deepen into the L2 migration contexts due to the importance that human mobility has got in the contemporary era.

Finally, from a different perspective, it is relevant to mention the suggestion of Henry (2017), who says that in an always more multicultural and multilingual world, the concept of the Ideal L2 Self should be reconceptualized, and the accent should be put over considering the development of Ideal Multilingual Selves. This should also be taken into account by considering that the idea of multilingual speakers is comprised of the model of instruction and communication contemplated by the Council of Europe (Henry, 2017; Ushioda, 2017).

\section{Methodology}

The aim of the present study is to fill the gap in the LOTEs motivation research. More in detail, we consider the need for more attention towards language learning motivation in the migration context. As already discussed in the previous chapter, the literature in this regard is very scarce. Furthermore, to the best of our knowledge, there is a lack of specific studies regarding the L2 learning motivation of refugees. In this work, we want to analyze the specificity of this learners' group language motivation, as we believe it is an independent class of learners. Since they are forced migrants, their migration path is not deliberately decided, but it is often due to force majeure. This brings them to live in a country that they often did not choose. Moreover, refugees' stay in the host country is often temporary and also conditioned by the factors that have caused the migration (wars, persecutions, environmental disasters, etc.) (Galli, 2017). These conditions distinguish them from other migrants, e.g. economic migrants, who often plan to settle in the country of the L2 permanently. On the contrary, refugees often plan to leave the host country for improving their life or to join family components or friends in other countries.

In this study, we investigate the language attitudes and the factors that are linked with the Italian language learning motivation of adult refugees in Italy. In order to choose the most suited methodology to conduct this study, from one side, we considered the methodologies that were used in the literature, and, from the other side, we examined the context of analysis through participant observation. Both ways helped us to elect a suitable methodology for the specific case of adult refugee learners in Italy.

As Boo, Dörnyei, and Ryan (2015) show, in the studies conducted starting from 2005, most of the research in L2 learning motivation is done by using a quantitative methodology (178 out of 335 studies), with a minority of qualitative (71), mixed methods (73) and innovative methods (13). Nevertheless, in their literature review, they showed that there is increasing use of the qualitative methods (interviews, observation, and discourse analysis) in the last period.

For our study, we have decided to conduct an ethnography. More specifically, we have used interviews and qualitative questionnaires. The choice was taken after a period of participative observation in L2 Italian classes frequented by refugees and immigrants and was due mainly to three reasons. First, in the classes of the observation, there were numerous refugees coming from West African countries or Asian countries with a very low level of education, often illiterates. This condition left a small room for the use of quantitative methods such as the questionnaire on a largescale, which seems to not be applicable to this type of learner. The second reason that drove us to choose this method is the need for a deep understanding of the learning motivation of these students. In this sense, the qualitative approach is considered optimal, as it allows us to get close to the informants and deepen their motivation of

XLinguae, Volume 13 Issue 4, October 2020, ISSN 1337-8384, ISSN 2453-711X 
learning the language of the host country (Alvarez Alvarez, 2008; Goetz, LeCompte, 1998). The third reason is probably the one that relates the most to the need for a qualitative approach with adult refugee students. In fact, the reason lies in the peculiar situation of being a refugee. The administrative situation of being a refugee implies that the main relations that these persons establish with locals are linked to their status. That means that in the host country, they mainly talk to lawyers, police, and mediators. This particular situation calls attention to new ethical issues derived from the migration (Mahrik, Kralik, Tavilla, 2018). That is, such circumstances can drive refugees to feel stressed and anxious when being 'asked questions'; thus, their answers could be affected. For this reason, this situation requires from the researcher a soft and gradual approach to them in order to be able to establish a trust relationship that can lead to a deep look into the subject of analysis. In this sense, the observation that we have conducted as a previous stage of research served as the first way to approach them and establish a trust relationship with them.

\section{Informants and research instruments}

The present study was based in Puglia region, in the south of Italy. Our informants were 47 adult refugees with whom we have conducted 28 interviews and 27 questionnaires. Their country of origin is various and distributed in the following way: Nigeria (11), Gambia (7), Pakistan (6), Senegal (3), Bangladesh (3), Ivory Coast (3), Guinea Bissau (2), Guinea (2), Somalia (2), Syria (2), Egypt (1), Niger (1), Mali (1), Sierra Leone (1), Ghana (1), Mauritania (1).

The qualitative questionnaire used for this study consisted of 54 open and closed questions and has been structured into three parts: one referred to language learning motivation and expectations, one addressing the use of the spoken languages, and one regarding the relationship of the students with the Italian language. Due to the presence of low educated and illiterate students, the questionnaires were administered in both written and oral form. Moreover, because of the low level of Italian language, the questionnaires were administered in Italian, English, French, and Arabic, taking into consideration the lingua franca of the students. Similarly, lingua franca was also used during the interview sessions. Semi-structured interviews have been chosen as a research instrument in order to allow a natural and relaxed way to deepen into the student motivation and relation with languages. The interview protocol was developed starting from the questionnaire questions, and it had the intention to elicit open and indepth answers. Both questionnaires and interviews did not focus only on Italian language learning but took into consideration the whole language learning motivation of the refugee students, thus considering also other eventual languages.

\section{Results}

In the following sections, we present the results obtained from the analysis of the data. The data have been analyzed after being codified and divided into meaningful categories, according to the principles of the grounded theory (Olabuenaga, 1996). This interpretative approach leads us to the identification of the factors that influence the motivation of adult L2 refugee students in Italy. The factors have been combined into groups by following the existing paradigm, taking into consideration the works of Dörnyei (2005) and Taguchi, Magid, and Papi (2009). However, we have included other new components that we have considered relevant for being meaningful and specific for the case of adult refugee learners. For these new components, we have considered the theories of Schumann (1976), Krashen (1982), and Henry (2017). Six major groups combine the factors found in this study: Ideal L2 Self, Ought-to L2 Self, Social Distance, Learning Experience, Self-confidence and Anxiety, and Multilingual Self. 


\section{Ideal L2 Self of adult refugee learners of Italian L2}

In some situations, the interviewed refugees showed a positive attitude toward the L2 country, because they consider that living in Italy is a substantial positive change in their living conditions. That was proven by the words of Mamadou (the names are pseudonyms to ensure anonymity), a young Ivorian refugee who flees his country since a few months. He says: "I feel good (in Italy) because nobody denies my freedom". Such positive attitudes and proves of wellbeing in Italy, are often the basis for shortening the distances and learning more about the L2 country. This translates into the need to integrate into the new country and partially becoming part of it. That is what Ahmad shows by saying that "I want to learn Italian because if I speak Italian, I can talk to people and learn more about Italian culture and traditions. I am living here now, and I need to know well how life is here".

From another point of view, since Italian is the language of the country where these refugees live and are able to study, the language becomes the instrument for building their future through better education. As Mohammad says, "I want to study till university. That will help me in my future... I take this course because of my future. I want to study in Italy and that course will help me to continue my education... It is very important to write well Italian so that I can get good marks in exams".

Surely, for living in the L2 country, all the life of the refugees is related to the L2. For this reason, the L2 motivation is linked with personal outcomes like work ambitions and study. Similarly, L2 learning motivation is linked with the necessity of satisfying practical needs like being able to communicate with the doctor or solve practical issues related to immigration status. Surely, these needs and ambitions are linked with the desire to integrate into the new country. In this sense, the integrative factor is fundamental, as the willingness (or not) of the learner to integrate into the new country is often related to the willingness to learn the $\mathrm{L} 2$.

In sum, the motivation factors that emerge from the ethnography relate to the future L2 image of the refugee, as well as his attitudes towards the new country, its community, and its cultural products and language. From another point of view, another L2 motivation factor refers to the need to learn the language in order to achieve a personal goal. Moreover, it has to be noted that since refugees live in the geographical area of the L2, another factor refers to the L2 motivation is derived from the integration needs. That is because the refugees feel the need to know more about the L2 country's culture and traditions.

More in details, we have identified eleven factors that can be related to the concept of the Ideal L2 Self dimension Dörnyei (2005):

- (1) Future work in Italy;

- (2) Future education in Italy;

- (3) Future family in Italy;

- (4) Future friendships in Italy;

- (5) Being a future speaker of Italian;

- (6) Writing ability in Italian;

- (7) Reading ability in Italian;

- (8) Understanding Italian TV and newspapers;

- (9) Knowledge about Italian traditions and culture;

- (10) Knowledge about the politic situation in Italy;

- (11) Ability to solve daily problems alone (e.g. doing shopping, going to the doctor, or dealing with bureaucratic issues).

Some of these factors seem to be specific to the context of learning a language in its original geographical area as they relate to the integration of the students in that society. Hence, they have not been taken into consideration in previous studies due to the fact that language learning motivation research has been mainly based in foreign language contexts (Boo, Dornyei, and Ryan, 2015). However, in order to combine

XLinguae, Volume 13 Issue 4, October 2020, ISSN 1337-8384, ISSN 2453-711X 
such factors in bigger groups of meaning, we propose here an identification with the dimensions defined by Dörnyei (2005) and Taguchi, Magid, and Papi (2009) as:

- Ideal L2 self image (1, 2, 3, 4, 5, 6, 7);

- Attitudes towards Italian L2 language, culture, and community $(9,10)$;

- Instrumentality promotion $(1,2,3,8,11)$;

- Integrativeness $(1,2,3,4,9,10,11)$.

\section{Ought-to L2 Self of adult refugee learners of Italian L2}

Often, during this research, we have observed that the peculiar condition of the refugees as forced migrants put them into a "forced living conditions situation" that can coincide with forced L2 learning. That is to say, not all refugees that live in Italy aspire to learn the Italian language; some of them feel forced by the situation, as they do not have other choices, though they could not reach the desired country and are legally obliged to stay in Italy. Furthermore, the existing assimilation pressure exerted by the governments put the accent on the integration of the immigrants through language learning. Such assimilative pressure is present in all Europe, and it is widely supported by specific rules defining the linguistic duties of the immigrants in order to enter or stay in a European country (Pulinx, Van Avermaet, Extramiana, 2014).

Surely, because of these conditions, L2 refugee learners are very different from FL students. A foreign language learner usually studies the language because of cultural or educative reasons, the language is often chosen by him deliberately, and the main external learning pressure that can move his motivation derives from the parents' expectations. On the contrary, in the case of L2 refugee learners, the external expectations factors are various. Thus they have much more influence on refugees' motivation.

According to the L2 refugee learners' situation, the obligations derived from the external expectations (the Ought to L2 Self dimension, in Dornyei, 2005) are a major component of the L2 learning motivation between refugees. More specifically, we have identified the following components:

- (1) Social expectations;

- (2) National expectations;

- (3) Hosting organization expectations;

- (4) Family expectations.

Each of these four components represents an independent external entity that influences refugee motivation. Hence, the dimension of the Ought-to L2 Self of refugees seems to be formed by various components, which could confirm what is suggested by Dörnyei and Al-Hoorie, (2017) about the existence of various Ought-to L2 Selves in L2 learning situations.

In addition to these factors, we can also consider the inclusion of an Instrumentality Prevention component, as it has been done by Taguchi, Magid, and Papi (2009). Nevertheless, since in this context, it would be rather hard to discuss every single factor, we prefer to focus our attention on the external expectation factors, as they are peculiars for the adult refugee learners.

Definitely, the external expectations are a determinant factor between refugees, especially when they find themselves in a forced living situation. This is because some of the refugees of this study were headed to other countries but had to live in Italy due to the Dublin regulation (EU 604/2013). According to this law, the refugee has to be taken in charge by the country of his first entrance. In other words, some of them did not plan to live in Italy. Hence they did not plan to learn the Italian language as well. It is the case of Ahmad, who says, "Austria is better, there is a job there. I have been in Austria for some months, but they made me go back because they took my fingerprints here". 
In addition to this, most of the refugees speak English or other Linguas Francas (that are national languages in their home countries). Thus, they would be potentially able to communicate with the locals through global English or other Linguas Francas. However, this ethnography shows that they are forced to learn Italian for not finding Italian speakers of these languages. The case of Bamba serves as an example between the various refugees that expressed very similar feelings. Bamba plans a future in northern Europe, and his stay in Italy is temporary due to the lack of work. When talking about language learning, he says, "Living in Italy is not easy because I don't understand what people say. If I read something on the wall, I can't understand. At home, I speak English, and I can talk with Pakistani, Nigerians, all. But out... I have to learn Italian because Italian people do not speak English. When I try to talk to them they always say italiano, italiano!". Very similar is the case of Jess. This refugee from Ghana origins expressed her disappointment because she perceives that foreign people in Italy are given a diminished value if they are not able to speak the local language. She exactly says: "living here without the language. You are nothing".

Another factor that influences refugees' L2 learning motivation in Italy is the pressure exerted from the refugees hosting agency. A clear example is given by the words of Babu, when talking about the workers of the organization that hosts him: "we are many students, some people never studied. Others are good. They can speak. For me it's very hard. (...) I want to go work. No study. But my teacher says if I don't go school she doesn't give me the money". In this case, the teacher is also a worker of the organization and she controls the distribution of the weekly food ticket. In order to 'motivate' the students to go to lessons, she threatens them that she would not give the money if they do not follow the course.

Another point we want to address in this section is the influence exerted by the family, which deserves here special attention. Differently from what happens for the FL learners (see e.g. Taguchi, Magid, Papi, 2009), the L2 refugee learners seem to be rarely affected by the family influence. That is because in most of the cases refugees have reached alone the L2 country. However, there are cases in which they live with one or more family members. These are usually not influential in their language learning unless they are their sons. A demonstration is given by the case of Ahmad, who has two very young children and when referring about it, he says: "I need to learn Italian. My sons are growing here, and soon they will speak Italian. They will speak like Italians. I need to help them in the school, talk with their teachers, you know, everything...". Hence, the family influence on these cases is different than the influence exerted by the family expectations of the FL learners. Furthermore, it is important to note that the influence exerted in these cases from the sons of a student may also be correlated with the Ideal L2 Self dimension, being a promotional factor, rather than a duty correlated with the Ought-to L2 Self dimension.

\section{Social distance}

As extensively discussed in this paper, integrativeness is an important factor when talking about L2 learners, more than it is for FL learners. However, integration depends on multiple factors, one of which is the social distance between the newly arrived 'foreigner' and the local community. According to the social distance concept of Schumann (1976), the L2 learning of the newly arrived immigrant depends on the relations between the two groups (that of the L2 learner and that of the L2 community). That is, the social distance is affected by the social status of the two groups, as well as by the size and the cohesion of the L2 learner group. Besides this, the attitudes of the local community towards the L2 learner group can have an impact. Furthermore, Schumann also considers as an influencing factor the length of time that the L2 learner aims to spend in the L2 country. This means that, according to his theory, one

XLinguae, Volume 13 Issue 4, October 2020, ISSN 1337-8384, ISSN 2453-711X 
would be more motivated to learn the L2 the more time he plans to spend in the L2 country.

In order to exemplify the influence of Schumann's theory in this context, we find it useful to cite some fragments of the interviews. The first refers to Schumann's idea on the attitudes of the L2 group towards the L2 learners' group. It is the case of Kevin's feeling of being an undesired presence in the country. He says, "People here don't like black people. When I walk in the street, they all look at me, but when I try to talk to them, they turn on the other side. Other times they tell me they don't understand me. I don't know why they hate us. We never did something bad to them".

Secondly, another relevant aspect for our study is the refugees' temporary permanence in the L2 country, which reminds us of the Schumann idea according to which the more you intend to stay in a country, the more you are motivated to learn its language. In this regard, it has to be said that refugees often do not have a wellestablished migration project. That is due to the reasons for which they have left their countries, often without being able to make any plan. Hence, sometimes they move from the host country and continue their migration. That it can happen, for example, because they need to join other family components in other countries or simply because they decide to go elsewhere. In fact, many refugees plan to live somewhere else due to the lack of jobs in Italy. It is the case of Javed, who comments: "I am waiting my papers, then I will go somewhere else. I will go France. Or maybe Spain. Italian people are good, but there is no job here". In these cases, the need of learning the L2 is only temporary, though it is greatly affected by these factors.

On the contrary, in other cases, Italy is the country to live in, hence refugees image themselves as a future part of the L2 community. It is the case of John, who plans to invest his efforts to learn Italian as he firmly desires to continue his life in this country. He says "Italy is my next home after I have been rejected in my country". The ideal L2 image of this refugee seems to correspond with a renegotiation of the refugee identity. That is because this refugee needed to flee his country and now aims at rebuilding a new life in the host country. Thus, in such cases Italy represents the new home, and as a consequence Italian language is the expression of a new self.

As our ethnography work shows, these facets are relevant when it comes to the analysis of the L2 learning motivation of refugees. Starting from Schumann's concept and the data extracted from our study, we observe that the following factors can influence the L2 learning of adult refugee students:

- Dominancy/Subordination of the L2 learner group face to the local group;

- Size of the L2 learner group;

- Negative attitudes of the locals towards the L2 learner group;

- Intended time of permanence in the L2 country.

\section{Learning Experience}

As for Dörnyei (2005), the learning experience, that is, the relation with teachers and classmates and the learning results, has an influence on the student learning motivation. In our specific case, we have found that the particular learning context causes a demotivation to the student due to learning conditions that do not favor the acquisition. What Ibrahim says when talking about his classroom is representative of the cases of many other refugees. When we asked him why he does not go to school anymore, he says: "there is no improvement; we study every day the same thing. For one year, she has been repeating the same lesson. (...) The Bangladeshi are always at the same point. The problem is they never went to school. So she always repeats the same things. Why should I go?".

\section{Self-confidence and Anxiety}

Self-confidence and anxiety are two factors that, according to Krashen (1982) can hinder the L2 learning. By the observation and the analysis of the data obtained from 
the ethnography, these two factors are widely related to the refugees' language learning in the host country, which is due to their particular situation and peculiarities. First of all, due to their origin, many refugees can suffer the stress of entering the education system at an adult age. In fact, a great proportion of the refugees living in Italy come from Western African countries, and many between them are illiterates or have very poor education levels. This condition affects their self-confidence, especially because different education level students often share the same classroom. As a consequence, this can generate low self-esteem and anxiety between them, as they see themselves on a lower level than their classmates. The case of Mariam is very indicative of the effect that these two factors can have on motivation, in fact, after going to school for a little more than one month, she left the course. In one of the interview sessions, she told us: "I never went to school. Never. I never went to school. I mean never ever. This is not easy for me. Others are good". According to her experience, which is very common among our students, the learning experience itself is the factor that influences the self-confidence and triggers the anxiety of the student. Nevertheless, it must not be forgotten that the administrative condition of the asylum seekers is alone a source of stress, this anxiety, which can surely affect the learning and motivation.

\section{Multilingual Self}

A final remark of this work is dedicated to the possibility of being motivated to learn more than a language. In 2017, Henry hypothesized that the concept of the Ideal L2 Self should be reconceptualized, in the view of an always more multilingual world. According to him, the accent should be put over the development of Ideal Multilingual Selves.

In this work, we have found that this concept meets the refugee linguistic world from two points of view. First, most of the refugees in this study are plurilingual. That is to say; besides learning Italian, they are able to speak one (or more) native language(s) and the national language (in most cases one between English, French or Portuguese) of their home country. Nevertheless, another characteristic of the refugees links their peculiar condition to the possibility of having Ideal Multilingual Selves. That is to say, refugees' migration path does often not complete in the host country. The case of Phil illustrates what a common case between refugees is. He says, "I want to learn Dutch because I am planning to move there. I know some people there. I want to work there and make my life there". We found that the idea of living in Holland is a common concept between Nigerians, exactly like Phil.

Similarly, many other refugees with other origins plan to leave Italy to search for a job or simply because they want to join relatives and friends who have migrated to another country. By planning to continue the migration, some of them, like Phil, want to learn a specific language, while others count on their knowledge of English as lingua franca. As previously discussed in this paper, the permanence of the refugee in a country is often temporary. Due to this, their language motivation can be multiple. Besides Italian language, they want to learn or use other languages. Accordingly, the motivation to speak other languages (and the temporariness of their stay in the host country) is potentially a factor that affects the motivation to learn the language of the host country. In this meaning, what we call here multilingual self, according to Henry (2017), seems to be a separate motivation component rather than the substitution of the ideal L2 self. Hence, we should consider the possible existence of ideal L3 self, ideal L4 self etc. taking into account that the Ideal $\mathrm{L}^{\mathrm{n}}$ selves could interfere with each other's motivation.

\section{Conclusion}

In the field of language motivation research, a growing interest is concerning the motivation regarding the study of a LOTE and that of an L2 studied in the country

XLinguae, Volume 13 Issue 4, October 2020, ISSN 1337-8384, ISSN 2453-711X 
where this language is spoken. In order to refer to the difference between the motivation of an L2 student and that of a FL student, the attentions of the research are being posed on whether the integrative factor could be more important for a learners group rather than for the other (Al Hoorie, 2017b; Gardner and Lambert, 1959). Besides, some remarks on possible future works are pointing out also the probable fragmentation of the Ought-to L2 Self factor between L2 learners (Dornyei, Al Hoorie, 2017). However, we consider that this subject has to be taken into account in a more holistic way. That is because not only the motivation of the L2 learners could differ from that of the FL learners, but also because special attention needs to be given to L2 learners in order to differentiate possible sub-groups. In this study, due to the peculiarity of their migration process, we decided to focus our research exclusively on L2 adult refugee learners.

The results of this work identify the L2 motivation factors in the Italian context of refugee second language learning. By taking into consideration the works of Dörnyei (2005), Taguchi, Magid, Papi (2009), Schumann (1976), Krashen (1982), and Henry (2017), we have combined the factors found in this research into six bigger groups, adding to the existing paradigm the concept of Social Distance, Self-confidence and Anxiety and Multilingual Self. In addition, we have identified specific factors of the L2 learning motivation between adult refugees for the already existing dimensions. The profiling of these dimensions aims to be a first contribution to the adaptation of the L2MSS to Italian L2 motivation context, for the specific case of adult refugee learners. In fact, the motivation factors found in this ethnography relate to the specific learning motivation of refugees that are due to their particular migration experience. However, the Ideal L2 Self dimension found here could relate to the second language learning motivation more generally in the whole migration context. That because the factors that compose this dimension refer to the need to speak the language in order to live in the L2 country, thus considering integrative reasons and future life projections in the L2 country, next to the own attitudes towards the L2 world. In this sense, the integrative reasons constitute an important share of this dimension, confirming the hypothesis of Al-Hoorie (2017b).

Nevertheless, in the specific field investigated here, more special attention needs to be given to the Ought-to L2 Self dimension. Refugee's second language learning seems to be moved, tough even forced sometimes, by duties. Various external pressures push the refugee to learn the L2. For living as a "foreigner" in another country, the community expects the refugee to speak their language, even when he is able to speak linguas francas. Similar is the influence exerted by the government of the host country and that of the hosting organization. A special reference needs to be made to the influence given by the family. This seems different than what has been demonstrated by previous studies (e.g. Taguchi, Magid, Papi, 2009), and even suggests that the family influence in these contexts is linked to the future image of oneself, rather than to an external expectation. On the other hand, the variety of entities that are implied in the ought-to L2 self dimension seems to confirm the hypothesis over the fragmentation of the ought-to L2 self in multiple factors (Dornyei, Al Hoorie, 2017).

From another point of view, strictly related to the case of adult refugees learning are the findings over the social distance influence, based on the theory of Schumann (1976). Specifically, the life of refugees is affected by the social differences and the negative attitudes carried out by the L 2 community towards the refugees. On the other hand, a relevant factor is constituted by the intended time of residence in the L2 country. In fact, refugees' permanence in the L 2 country is often temporary.

Another factor that deserves to be taken into account when researching refugees' motivation is the whole learning experience dimension. That because, as our study suggests, their specific difficulties can lead to problems of self-esteem and anxiety that can hinder the motivation or even lead the student to withdraw from the course. 
A final remark of this research concerns the need for considering, as already suggested by Henry (2017), the idea of multilingual selves. In light of this, this study demonstrates how the migration path of refugees can lead them to learn other languages, which can potentially trigger interactions between the languages' motivations. For this reason, it is suggested to consider the motivation for other languages as a new independent dimension.

\section{Acknowledgments}

This article was published with the support of the Slovak Research and Development Agency under contract No. APVV-17-0158.

The work is performed according to the Russian Government Program of Competitive Growth of Kazan Federal University.

\section{Bibliographic references}

AL HOORIE, A. 2017a. Implicit attitudes in language learning (Doctoral dissertation, University of Nottingham). Available online: http://eprints.nottingham.ac.uk/42571/ AL HOORIE, A. 2017b. Sixty years of language motivation research: looking back and looking forward. In: SAGE Open, vol. 7, n. 1, pp. 1-11. ISSN 2158-2440

ALVAREZ ALVAREZ, C. 2008. La etnografia como modelo de investigacion en educacion. In: Gazeta de Antropologia, vol. 24, n. 1, pp. 1-15. ISSN 0214-7564

BALBONI, P. 2012. Le sfide di Babele. Torino: UTET università. ISBN 978-88-6008453-8

BOO, Z. - DORNYEI, Z. - RYAN, S. 2015. L2 motivation research 2005-2014: understanding a publication surge and a changing landscape. In: System, vol. 55, pp. 145-157. ISBN 0346-251X

CHARTRAND, T. L. - DALTON, A. N. - FITZSIMONS, G. J. 2007. Nonconscious relationship reactance: when significant others prime opposing goals. In: Journal of Experimental Social Psychology, vol. 43, pp. 719-726. ISSN 0022-1031

CLEMENT, R. - BAKER, S. C. 2001. Measuring social aspects of L2 acquisition and use: social characteristics and administration (technical report). Ottawa: School of Psychology, University of Ottawa.

DE MAURO, T. - VEDOVELLI, M. - BARNI, M. - MIRAGLIA, L. 2003. Italiano 2000. I pubblici e le motivazioni dell'italiano diffuso fra stranieri. Roma: Bulzoni. ISBN 8883197976

DORNYEI, Z. 2010a. Researching motivation: from integrativeness to the ideal L2 self. In S. Hunston - D. Oakey (Eds.), Introducing applied linguistics: concepts and skills. London: Routledge. pp. 74-83. ISBN 0415447682

DORNYEI, Z. 2010b. Questionnaires in second language research: Construction, administration, and processing (2nd ed.). London: Routledge. ISBN 0-8058-3908-9

DORNYEI, Z. 2009. The L2 Motivational Self System. In Z. Dornyei - E. Ushioda (Eds.), Motivation, language identity and the L2 self. Bristol, UK: Multilingual Matters. pp. 9-42. ISBN 9781847691279

DORNYEI, Z. 2005. The psychology of the language learner: individual differences in second language acquisition. London, UK: Lawrence Erlbaum. ISBN 0805860185

DORNYEI, Z. 2001. Teaching and researching motivation. Harlow: Longman. ISBN 1408205025

DORNYEI, Z. - AL-HOORIE, A. 2017. The motivational foundation of learning languages other than global English: theoretical issues and research directions. In: Modern language journal, vol. 101, n. 3, pp. 455-468. ISSN 15404781

DORNYEI, Z. - CSIZER, K. 2002. Some dynamics of language attitudes and motivation: results of a longitudinal nationwide survey. In: Applied linguistics, vol. 23, n. 4, pp. 421-462. ISSN 0142-6001

XLinguae, Volume 13 Issue 4, October 2020, ISSN 1337-8384, ISSN 2453-711X 
DORNYEI, Z. - CSIZER, K. - NEMETH, N. 2006. Motivation, language attitudes, and globalisation: a Hungarian perspective. Clevedon: Multilingual Matters. ISBN 978-1853598852

DORNYEI, Z. - RYAN, S. 2015. The psychology of the language learner revisited. New York: Routledge. ISBN 978-1138018747

DORNYEI, Z. - USHIODA, E. 2011. Teaching and researching motivation (2nd ed.). Harlow, UK: Pearson. ISBN 978-1408205020

GALLI, T. 2017. La logica del sistema di accoglienza dei richiedenti protezione internazionale e la sua ricaduta sull'apprendimento dell'italiano. In: Bollettino Itals, vol. 68, pp. 14-38. ISSN 2280-6792

GARDNER, R. C. 2010. Motivation and second language acquisition: the socioeducational model. New York: Peter Lang. ISBN 978-1433104596

GARDNER, R. C. 1985. Social psychology and language learning: the role of attitudes and motivation. London: Edward Arnold.

GARDNER, R. C. - LAMBERT, W. E. 1959. Motivational variables in second language acquisition. In: Canadian Journal of Psychology, vol. 13, pp. 266-272. Available online [March, 10, 2019]: https://eric.ed.gov/?id=ED031968

GOETZ, J. P. - LECOMPTE, M. D. 1998. Etnografia y diseno cualitativo en investigacion educativa. Espana: Morata. ISBN 9788471123206

HENRY, A. 2017. L2 motivation and multilingual identities. In: Modern Language Journal, vol. 101, pp. 548-565. ISSN 15404781

HIGGINS, E. T. 1987. Self-discrepancy: A theory relating self and affect. In: Psychological Review, vol. 94, pp. 319-340. Available online [March, 10, 2019]: http://persweb.wabash.edu/facstaff/hortonr/articles\%20for\%20class/Higgins.pdf

KOBYLAREK, A. 2010. Integration of Elderly Citizens through Learning. In: New Educational Review, vol. 22, n. 3-4, p. 24. ISSN 1732-6729.

KRASHEN, S. D. 1982. Principles and practice in second language acquisition. Oxford: Pergamon. ISBN 0-08-028628-3

LAMBERT, W. E. 1969. Psychological aspects of motivation in language learning. Bulletin of the Illinois foreign language teachers association, May, pp. 5-11.

LANVERS, U. 2017. Contradictory others and the habitus of languages: surveying the L2 motivation landscape in the United Kigdom. In: Modern Language Journal, vol. 101, n. 3, pp. 517-532. ISSN 15404781

LI, Q. 2014. Differences in the motivation of Chinese learners of English in a foreign and second language context. In: System, vol. 42, n. 1, pp. 451-461. ISSN 0346251X MAHRIK, T. - KRALIK, R. - TAVILLA, I. 2018. Ethics in the light of subjectivity Kierkegaard and Levinas. In: Astra Salvensis, vol. 6, n. 2, pp. 488-501. ISSN: 23934727

MARKUS, H. - NURIUS, P. 1986. Possible selves. In: American Psychologist, vol. 41, pp. 954-969.

NEULIEP, J.W. - MCCROSKEY, J.C. 1997. The development of a U.S. and generalised ethnocentrism scale. In: Communication Research Reports, vol. 14, n. 4, pp. 385398. ISSN 0882-4096

NOELS, K.A. - PELLETIER, L.G. - CLEMENT, R. - VALLERAND, R.J. 2000. Why are you learning a second language? Motivational orientations and selfdetermination theory. In: Language Learning, vol. 50, n. 1, pp. 57-85. Available online:http://selfdeterminationtheory.org/SDT/documents/2003_NoelsPelletierClemen tVallerand_LL.pdf

OLABUENAGA, R. J. I. 1996. Metodologia de la investigacion cualitativa. Bilbao: Universidad de Deusto. ISBN 9788498303360

OXFORD, R. L. 1996. New pathways of language learning motivation. In: R. L. Oxford (Ed.), Language learning motivation: pathways to the new century. Honolulu, HI: University of Hawaii Press. pp. 1- 8. ISBN 978-0824818494 
OXFORD, R. - NYIKOS, M. 1989. Variables affecting choice of language learning strategies by university students. In: Modern Language Journal, vol. 73, n. 3, pp. 291300.

Available

online :https://www.jstor.org/stable/327003?seq=1\#metadata_info_tab_contents

PAPI, M. 2010. The L2 motivational selfsystem, L2 anxiety, and motivated behaviour: a structural equation modelling approach. In: System, vol. 38, n. 3, pp. 467-479. ISSN 0346-251X

PULINX, R. - VAN AVERMAET P. - EXTRAMIANA, C. 2014. Linguistic integration of adult migrants: Policy and practice. Final report on the 3rd Council of Europe Survey. Strasbourg: Council of Europe. Available online [March, 10, 2019]: https://rm.coe.int/16802fc1ce

RYAN, S. 2009. Self and identity in L2 motivation in Japan: the Ideal L2 Self and Japanese learners of English. In Z. Dornyei - E. Ushioda (Eds.), Motivation, language identity and the L2 self. Bristol: Multilingual Matters. pp. 120-143. ISBN 9781847691279

SCHUMANN, J. H. 1976. Social distance as a factor in second language acquisition. In: Language learning, vol. 26, pp. 135-143. Available online: https://onlinelibrary.wiley.com/doi/pdf/10.1111/j.1467-1770.1976.tb00265.x

SUGIHARTO, S. 2015. Disentangling linguistic imperialism in English language education: the Indonesian context. In M. Bigelow - J. Ennser-Kananen (Eds.), The Routledge handbook of educational linguistics. New York: Routledge/Taylor \& Francis. pp. 224-236. ISBN 9780415531306

STRACKE, E. - JONES, J. - BRAMLEY, N. 2014. Investigating adult migrant ESL learners' language learning motivational profile in Australia: towards a bicultural identity. In K. Csizer - M. Magid (Eds.), The impact of self-concept on language learning. Bristol: Multilingual Matters. pp. 155-170. ISBN 9781783092369

TAGUCHI, T. - MAGID, M. - PAPI, M. 2009. The L2 Motivational Self System among Japanese, Chinese and Iranian learners of English: a comparative study. In Z. Dornyei - E. Ushioda (Eds.), Motivation, language identity and the L2 self. Bristol: Multilingual Matters. pp. 66-97. ISBN 9781847691279

USHIODA, E. 2017. The impact of global English on motivation to learn other languages: toward an ideal multilingual self. In: Modern language journal, vol. 101, n. 3, pp. 469-482. ISSN 15404781.

USHIODA, E. - DORNYEI, Z. 2017. Beyond global English: motivation to learn languages in a multicultural world: introduction to the special issue. In: Modern language journal, vol. 101, n. 3, pp. 451-454. ISSN 15404781

YASHIMA, T. - ZENUK-NISHIDE, L. - SHIMIZU, K. 2004. The influence of attitudes and affect on willingness to communicate and second language communication. In: Language Learning, vol. 54, n. 1, pp. 119-152. ISSN 1467-9922

YOU, C. - DORNYEI, Z. 2014. Language learning motivation in China: results of a large-scale stratified survey. In: Applied Linguistics, vol. 37, pp. 495-519. ISSN $1477450 X$

ZALEC, B. - PAVLIKOVA, M. (2019). Civic virtues and functions of religion in public life. In: European Journal of Science and Theology, vol. 15, n. 6, pp. 75-84. ISSN $1842-8517$.

Words: 10082

Characters: 62825 (34.90 standard pages)

XLinguae, Volume 13 Issue 4, October 2020, ISSN 1337-8384, ISSN 2453-711X 
Mónica Ortiz Cobo

Faculty of Political Sciences and Sociology

Department of Sociology

University of Granada

C/Rector López Argüeta, S/N

18007 Granada, Spain

monicaoc@ugr.es

Prof. Roman Kralik, PhD.

Contantine the Philosopher University in Nitra,

Nitra, Tr. A. Hlinku 1

94904 Nitra

Slovak Republic

Institute of Psychology and Education

Kazan (Volga region) Federal University

18 Kremlyovskaya Str 420008,

Kazan

Russia

kierkegaaard@ centrum.cz

Rosella Bianco (corresponding author)

Institute of Migrations

University of Granada

Polígono Tecnológico Ogíjares

Calle Zamora. Parcela 111-112

18071 Granada

Spain

rosellabianco@correo.ugr.es 